\title{
Application of three-dimensional reconstruction technology in congenital anomalies of the kidney and urinary tract: a case description
}

\author{
Yang Cui ${ }^{1}$, Yan Chen ${ }^{1}$, Jin Zhao $^{2}$ \\ ${ }^{1}$ Department of Urology, Shijiazhuang People's Hospital, Shijiazhuang, China; ${ }^{2}$ Department of Blood Transfusion, Hebei Provincial People's \\ Hospital, Shijiazhuang, China
}

Correspondence to: Yan Chen. Department of Urology, Shijiazhuang People's Hospital, No. 365, Jianhua south Street, Shijiazhuang, China. Email: 81383077@qq.com.

Submitted Jul 04, 2021. Accepted for publication Sep 24, 2021.

doi: 10.21037/qims-21-691

View this article at: https://dx.doi.org/10.21037/qims-21-691

\section{Introduction}

Congenital anomalies of the kidney and urinary tract (CAKUT) can affect $3.3-11.1 \%$ of the population and are associated with gene mutation, gene copy number variation, and environmental factors (1). Kidney malformation has multiple clinical manifestations, including renal underdevelopment, renal dysplasia, renal hypoplasia, polycystic renal dysplasia, ectopic kidney, and horseshoe kidney. Most congenital anomalies can be detected by ultrasound (US), computed tomography (CT), magnetic resonance imaging (MRI), or three-dimensional (3D) imaging. Image reconstruction technology shows kidney deformities more clearly with better spatial resolution (2). In this case report, we used 3D technology to clarify a rare type of renal deformity.

\section{Case presentation}

All procedures performed in studies involving human participants were in accordance with the ethical standards of the institutional and/or national research committee(s) and with the Helsinki Declaration (as revised in 2013). Written informed consent was obtained from the patient for publication of this case report and accompanying images. A copy of the written consent is available for review by the editorial office of this journal.

A 45-year-old woman was admitted to hospital complaining of a 1-month history of dizziness, and a transient ischemic attack was diagnosed. During a lung examination, her left kidney was found to be abnormal. The patient was not known to have kidney abnormalities, and there was no genetic history of this condition in her family. The patient did not present clinical symptoms of low back pain, hematuria, or urinary tract infection, and laboratory tests of renal function and urine routine were within normal ranges. The patient had no history of hypertension. A CT plain scan showed abnormalities in the left renal artery, vein, and ureter, and a reversed renal parenchyma with the collecting system protruding, while the right kidney was completely normal. Enhanced CT suggested that there was an artery in the left kidney, which entered the renal parenchyma in a mesh shape. There were 2 primary thick branches of deep veins, which merged with the reproductive vein at the renal pedicle and then merged into the inferior vena cava. The renal parenchyma was in a state of eversion and folding, and the renal papilla was prominent. Each renal papilla corresponded to a renal calyx, which converged into the renal pelvis on the ventral side (Figures 1,2). Using a software application (Mimics Innovation Suite 19.0, Materialise, Leuven, Belgium), we created a $3 \mathrm{D}$ reconstruction of the patient's kidneys. The 3D-reconstructed images (Figures 3,4) showed that the right kidney was normal in anatomy and that the left kidney was abnormal. In Figures 3,4, it can be seen more intuitively and clearly that the left kidney has poor rotation, irregular physical contours, and an uneven surface; the renal pelvis and ureter are distributed in a "Y" shape. The final 


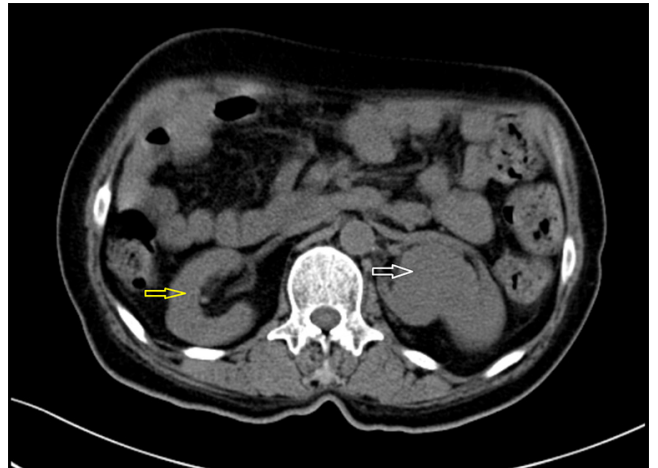

Figure 1 A plain computed tomography scan shows that the right renal parenchyma (yellow arrow), blood vessels, and collecting system are completely normal, while the left renal parenchyma (white arrow) is abnormal, with the collecting system protruding.

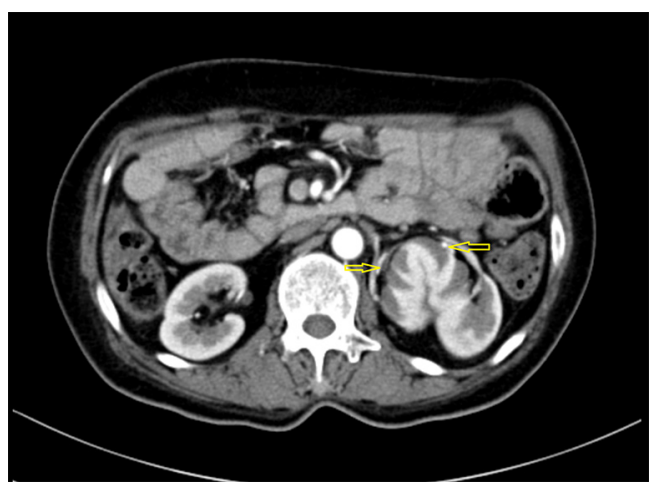

Figure 2 Enhanced computed tomography suggests that there is an artery in the left kidney that enters the renal parenchyma in a mesh shape (yellow arrow).

clinical diagnosis was CAKUT, and the patient's clinical symptoms disappeared after conservative treatment. As the patient had no urinary system discomfort and her physical and laboratory examinations were normal, we prescribed a dynamic observation treatment plan with annual renal function and urinary system USs.

\section{Discussion}

At present, US, CT, and MRI techniques are widely used in the clinical diagnosis of congenital urinary tract abnormalities. Due to the advantages of simplicity, noninvasiveness, and nonradioactivity, US has been widely used in the field of perinatal diagnosis and newborn screening. Li et al. used US to screen 2,655 newborns, of

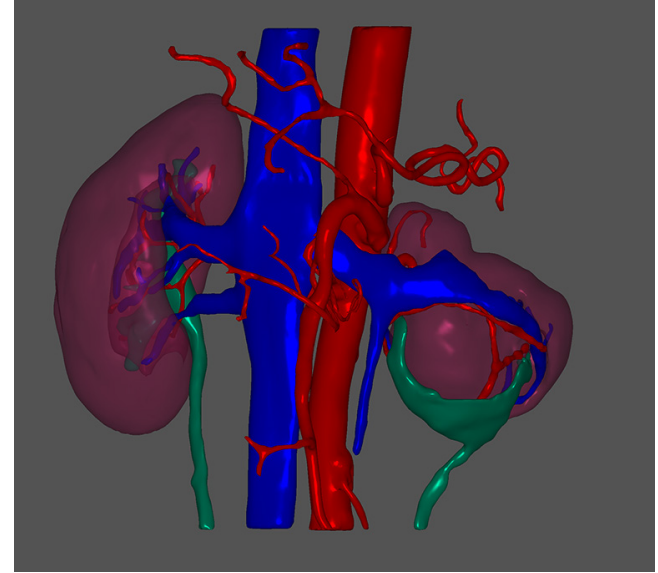

Figure 3 A front view of the kidney after three-dimensional (3D) reconstruction shows that the left kidney has poor rotation, irregular physical contours, and an uneven surface, with malformed blood vessels and collecting system.

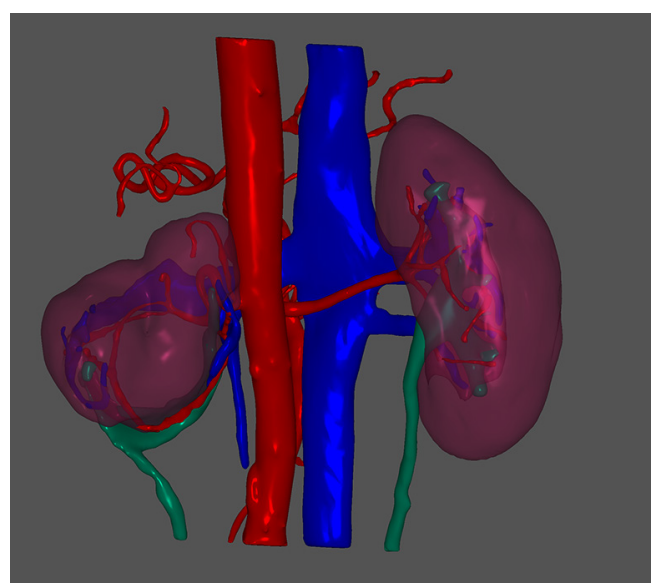

Figure 4 The back of the kidney after three-dimensional (3D) reconstruction shows that the ureter is distributed in a " $\mathrm{Y}$ " shape.

whom 82 were diagnosed with CAKUT (60 males and 22 females), giving a positive rate of $3.1 \%(82 / 2,655)$ (3). US provides a clear image of the details of the deformity, including position, number, shape, and confluence. Meanwhile, enhanced CT can be used to display the reconstruction of blood vessels, the renal parenchyma, renal pelvis, ureter, and intestine to facilitate surgery.

Moreover, MRI water imaging is gradually replacing intravenous pyelogram (IVP) and becoming the primary method for diagnosing ureteral abnormalities (4). MRI is generally superior to CT due to the lack of ionizing 
radiation exposure although a study on Bosniak IIF lesions of renal cysts showed that the risk of radiation-induced cancer in CT monitoring has little effect on life expectancy (5). The most commonly used examination for diagnosing congenital urinary tract abnormalities is currently $2 \mathrm{D}$ US examination, and while $3 \mathrm{D}$ US has a radiation-free advantage in measuring kidney volume, its accuracy is still far behind that of MRI and CT, and more research is needed in the future (6).

$3 \mathrm{D}$ printing imaging technology, which originated in the 1980s, uses polymer bondable materials, such as powdered metal or plastic, to construct objects by printing them in layers. This technology has a wide range of clinical applications in the medical field, including medical teaching, surgical model planning, and organ bioprinting. In one study on 3D printing, patients who viewed their personal 3D kidney model demonstrated a $16.7 \%$ improvement in their understanding of basic kidney physiology $(\mathrm{P}=0.018)$, a $50 \%$ improvement in understanding kidney anatomy $(\mathrm{P}=0.026)$, a $39.3 \%$ improvement in understanding tumor characteristics $(\mathrm{P}=0.068)$, and a $44.6 \%$ improvement in understanding the planned surgical procedure $(\mathrm{P}=0.026)(7)$. $3 \mathrm{D}$ printing in the case of a patient with a horseshoe kidney tumor before surgery showed abnormal blood vessels, and the tumor was successfully removed (8). Based on CT and MRI data, 3D reconstruction and printing technology can be applied in surgical planning, patient education, and rare or complex cases, and has the potential to be even more broadly used in the urology field (9).

In this case, we only performed a $3 \mathrm{D}$ reconstruction based on a plain scan with enhanced imaging. We did not create an actual 3D print due to cost. However, through $3 \mathrm{D}$ image reconstruction, we used computer software to provide a $3 \mathrm{D}$ explanation to the patient, which assuaged their concerns and doubts and helped develop an active monitoring treatment plan. The patient said that the 3D reconstruction technology allowed her to understand the kidney problems more intuitively and dispelled her worries about the disease.

In summary, traditional inspection techniques can be widely used in CAKUT inspections. As a new technology, $3 \mathrm{D}$ imaging and printing is conducive to disease recognition, perioperative preparation, and planning, and is thus worthy of further promotion.

\section{Acknowledgments}

Funding: None.

\section{Footnote}

Conflicts of Interest: All authors have completed the ICMJE uniform disclosure form (available at https://dx.doi. org/10.21037/qims-21-691). The authors have no conflicts of interest to declare.

Etbical Statement: The authors are accountable for all aspects of the work in ensuring that questions related to the accuracy or integrity of any part of the work are appropriately investigated and resolved. All procedures performed in studies involving human participants were in accordance with the ethical standards of the institutional and/or national research committee(s) and with the Helsinki Declaration (as revised in 2013). Written informed consent was obtained from the patient for publication of this case report and accompanying images. A copy of the written consent is available for review by the editorial office of this journal.

Open Access Statement: This is an Open Access article distributed in accordance with the Creative Commons Attribution-NonCommercial-NoDerivs 4.0 International License (CC BY-NC-ND 4.0), which permits the noncommercial replication and distribution of the article with the strict proviso that no changes or edits are made and the original work is properly cited (including links to both the formal publication through the relevant DOI and the license). See: https://creativecommons.org/licenses/by-nc-nd/4.0/.

\section{References}

1. Srinivas MR, Adarsh KM, Jeeson R, Ashwini C, Nagaraj BR. Congenital anatomic variants of the kidney and ureter: a pictorial essay. Jpn J Radiol 2016;34:181-93.

2. Alyaev YG, Bezrukov EA, Fiev DN, Sirota ES, Pesegov $\mathrm{SV}$, Byadretdinov IS. Application of $3 \mathrm{D}$ printing in urology. Urologiia 2017;(4):73-8.

3. Li NN, Ji LN, Chao S, Yuan K, Meng H, Huang ZY, Zhang HB. Ultrasound screening and follow-up study of congenital anomalies of the kidney and urinary tract in neonates. Beijing Da Xue Xue Bao Yi Xue Ban 2019;51:1062-6.

4. Surabhi VR, Menias CO, George V, Matta E, Kaza RK, Hasapes J. MDCT and MR Urogram Spectrum of Congenital Anomalies of the Kidney and Urinary Tract Diagnosed in Adulthood. AJR Am J Roentgenol 2015;205:W294-304. 
5. Kang SK, Turan EA, Eisenberg JD, Lee PA, Kong CY, Pandharipande PV. Microsimulation model of CT versus MRI surveillance of Bosniak IIF renal cystic lesions: should effects of radiation exposure affect selection of imaging strategy? AJR Am J Roentgenol 2014;203:W629-36.

6. DeFreitas MJ, Katsoufis CP, Infante JC, Granda ML, Abitbol CL, Fornoni A. The old becomes new: advances in imaging techniques to assess nephron mass in children. Pediatr Nephrol 2021;36:517-25.

7. Bernhard JC, Isotani S, Matsugasumi T, Duddalwar V, Hung AJ, Suer E, Baco E, Satkunasivam R, Djaladat H, Metcalfe C, Hu B, Wong K, Park D, Nguyen M, Hwang D, Bazargani ST, de Castro Abreu AL, Aron M, Ukimura O, Gill IS. Personalized 3D printed model of kidney and

Cite this article as: Cui Y, Chen Y, Zhao J. Application of three-dimensional reconstruction technology in congenital anomalies of the kidney and urinary tract: a case description. Quant Imaging Med Surg 2022;12(3):2158-2161. doi: 10.21037/ qims-21-691 tumor anatomy: a useful tool for patient education. World J Urol 2016;34:337-45.

8. Mercader C, Vilaseca A, Moreno JL, López A, Sebastià MC, Nicolau C, Ribal MJ, Peri L, Costa M, Alcaraz A. Role of the three-dimensional printing technology incomplex laparoscopic renal surgery: a renal tumor in a horseshoe kidney. Int Braz J Urol 2019;45:1129-35.

9. Esperto F, Prata F, Autrán-Gómez AM, Rivas JG, Socarras M, Marchioni M, Albisinni S, Cataldo R, Scarpa RM, Papalia R. New Technologies for Kidney Surgery Planning 3D, Impression, Augmented Reality 3D, Reconstruction: Current Realities and Expectations. Curr Urol Rep 2021;22:35. 